USA national committees. Research on the production of microbial food is included in the Czechoslovak, Philippine, Swedish, UK and USA programmes. South Korea proposes work on the nutritive value of seaweed. A similar series of projects on the separation or fermentative upgrading of protein from oilseeds, leaves, and other unused or underused materials appears in the Swedish, UK and USA programmes. Some of these projects were discussed in August I966 at a Working Group meeting of the IBP on 'Novel Protein Sources', held in Warsaw in conjunction with the Second International Congress of Food Technology. There is an account of the meeting in IBP News no. 7. Work on the improvement of conventional protein sources or on the extraction of protein from novel sources, done under the aegis of the IBP is now well advanced in Czechoslovakia, Sweden and UK; I have no information about the progress that has been made in the other countries.

The function of the IBP is to be useful. Its successes, whether they take the form of the introduction of new or improved crops or animals into a country, or of the preparation of novel forms of food, will be measured by the change that is made in the quality and character of the food people eat. A study of the resistance to change, and of the techniques for weakening it, will be an important future project for section HA. Similarly, section UM should consider, in concrete terms, what could be achieved in certain typical regions that are at present inadequately fed, if existing knowledge, and the knowledge that we hope will be gained during the course of the Programme, is fully applied. One of the great advantages of having an international programme is that there may be complementation between the different aspects of national character. It seems that we in Britain are peculiarly prompt at getting an organization going and research started; it is to be hoped that some other country will be more effective than we tend to be at getting the results applied.

\title{
The Human Adaptability Programme
}

\section{By O. G. EdHolm, Division of Human Physiology, National Institute for Medical Research (Hampstead Laboratories), London, $\mathrm{NW}_{3}$}

The Human Adaptability (HA) Programme is, broadly speaking, concerned with the ecology of man. In spite of many physiological, genetic and anthropological studies we are still profoundly ignorant of the way in which individuals and groups of mankind, with diverse cultures, adapt to their environment.

Since we are witnessing a rapid change in the pattern of life amongst a large proportion of the human population, there is a special urgency to study those peoples who still have a simple and traditional culture. There are few left today, and in a short time there may well be none. In Africa, south of the equator, the Bushmen of the Kalahari are probably the last surviving hunter-gatherer peoples, and their numbers as hunter-gatherers are rapidly declining (Tobias, I966). In the Arctic there are few Eskimo who have not substantially changed their habits as a result of contact with western civilization. In Australia the Aborigines are being rapidly absorbed, not only 
as workers on the farms but also in the cities. The story is a familiar one, but it would be tragic if such people were to disappear before effective research had been completed.

The basic pattern of the HA Section has already been suggested: it is to combine the work of physiologists, geneticists and anthropologists or anthropometrists. Although all three groups have done a good deal of field work, very rarely has there been even an overlap between the three disciplines. The few occasions when this has happened have proved how fruitful a multidisciplinary approach can be. The second point to stress is that the HA Section is part of the International Biological Programme (IBP), with emphasis on the word international. And there are two aspects of this word; within the programme there will be collaboration between nations and the development of multinational teams, but there will also be a number of national studies, usually of some particular aspect. It follows that thete is an overriding necessity to standardize agreed methods which all workers will use. This is far from easy, and indeed much of the work of the HA Section under the direction and guidance of the Convenor, Professor J. S. Weiner, has been concerned with the preparation of material for a handbook on agreed methods. This has been done by organizing a series of meetings where small international groups of experts have worked out suitable methods. In some cases agreement has been difficult, since widely different methods have been used by various workers. This has led to the organization of formal comparisons between methods in one or more suitable laboratories, and there can be no doubt that already much valuable and essential work has been done which would have been hard to carry out without the establishment of the IBP. During this preparatory phase, detailed plans have been drawn up, setting out the framework of the studies which it is hoped will be carried out in the HA programme. These are available in the first IBP Handbook (Weiner, 1965), with a contribution by Paul T. Baker. It would be tedious to reproduce these plans in detail, but a summary is necessary if the work on human adaptability is to be understood. The first need is to extend our knowledge of the various peoples of the world in terms of genetic polymorphic systems. The gaps at present are enormous. Although text books show maps illustrating the usual ABO blood group systems on a world-wide basis, even these, the most widely studied of all genetic markers, have only been measured in a small proportion of the world's population. As one example, Hiernaux (1966) has assembled the current knowledge of the blood groupings of the peoples of Africa north of the equator. In this region 603 ethnic groups have been identified, but satisfactory data on the ABO system exist for only seventy of them. There are, of course, many other genetic markers which can now be studied but which have been mapped on a much smaller scale.

In a similar way, we need world-wide knowledge of physique and growth. Again, the gaps are impressive. In the 603 ethnic groups referred to by Hiernaux, stature has been measured in only ${ }_{13}$, but stature and weight are available for the small number of twenty-four groups. More sophisticated measurements have scarcely been attempted in these particular populations. As far as growth is concerned, knowledge is also fragmentary; and yet, as Tanner ( 1966$)$ has pointed out, 'growth 
is one of the best indices of child health, and a continuous monitoring of the growth and development of children in under- and over-nourished populations is, or should be, a major concern of all public health authorities and governments.'

The next main category of HA studies is concerned with the multidisciplinary approach already mentioned. The full-scale study should include genetic, anthropometric and physiological aspects applied to the same ethnic group or groups. Since such studies involve sophisticated techniques they are time-consuming and expensive, and can only be carried out in limited numbers. For this reason the intention is to concentrate on ethnic groups of special interest. These include the hunter-gatherers whose numbers are diminishing rapidly, and groups living in environmental extremes of heat, cold and altitude. Wherever possible, areas of the world will be chosen where genetically similar groups are living in contrasting environments, or dissimilar groups live in the same locality. An example of such a study is given by Harrison (I966), who has already carried out a preliminary survey in Ethiopia. In the area examined, two groups were found who were shown to be genetically similar; one group lived at $5000 \mathrm{ft}$ and the second at $10000 \mathrm{ft}$. Although the vertical distance was considerable the horizontal distance was small. The results obtained indicate that there are significant differences between the groups in body form, in spite of apparent genetic identity. Detailed multidisciplinary studies of such groups will clearly be rewarding in terms of defining the effects of contrasting environments.

As well as these two broad categories of work planned by the HA Section, it is intended that there should be special studies, of a more limited nature, of selected population groups. These include aspects which form part of the multidisciplinary studies. The detailed list of such studies will be found in the IBP Handbook (Weiner, I 965 ). An example is the proposal to measure the physical working capacity of urban, non-urban and athletic groups of the population in a large number of countries.

Implied in the multidisciplinary and special studies is the need to have demographic and cultural studies of the ethnic groups examined. This should also include clinical information concerning disease patterns, both chronic and acute.

The position of nutritional studies in the context of the HA programme has been deliberately left to the last with the intention of discussing it in rather more detail.

An assessment of nutritional status is an essential feature of the growth and physique studies, and indeed of all the HA studies with the exception of the genetic surveys. The programme of the multidisciplinary studies includes a nutritional survey, with emphasis on calorie intake and expenditure. In neither the nutritional assessment nor the nutritional survey is nutrition itself the prime aim of the study. However, there is clearly an opportunity for examining the relationship between environment and food intake, when genetically similar groups are studied in different habitats. As an extension of this, it is proposed that calorie and protein intakes be measured in a whole series of habitats. The international agencies who are supporting and collaborating with the IBP include FAO, and the organization has urged the need for more information about protein requirements, particularly of children. Amongst the host of nutritional problems which could be studied within the IBP 
framework, this appears to be especially urgent and very suitable. There is already suggestive evidence that a low protein intake is compatible with good muscular development and capacity for relatively hard physical work. Macpherson (1966) has reviewed the work on nutrition which has been carried out in New Guinea. The main article of diet is the sweet potato, which has a low protein content, and in many regions animal protein is only rarely consumed. It appears likely that the total daily protein intake of adults may be no more than $30 \mathrm{~g}$ of vegetable protein. Yet men and women have a well-developed musculature and a capacity for hard physical work. At the same time there is ample evidence of protein deficiency in children and in pregnant women. This is a situation which provides a challenge to nutritionists, and where a combined study of dietary intake, energy expenditure and measurement of physical working capacity could be of the greatest value. Furthermore, a detailed record of child growth would considerably increase the value of such work.

There are many other examples which could be quoted of unusual dietary patterns that appear to be compatible with health. The word which needs emphasizing is 'appear'. In many instances the evidence available is fragmentary and of doubtful reliability. Sometimes it may be tempting to dismiss such evidence as a traveller's tale. The position will remain unsatisfactory if proper work is not initiated very soon, because the situation is changing rapidly. Are the travellers' tales all untrue? Can the desert dweller really tolerate a degree of dehydration which kills more ordinary people? There are a number of such problems which present a challenge to all those interested in human biology, and which surely we should attempt to solve. The IBP presents a unique opportunity to do this. The difficulties are obvious, particularly the shortage of trained personnel, as well as lack of money. But given the will these difficulties can be overcome, and the potential scientific rewards can scarcely be overestimated.

\section{REFERENCES}

Harrison, G. A. (1966). In The Biology of Human Adaptability, p.509. [P. T. Baker and J. S. Weiner, editors.] Oxford: Clarendon Press.

Hiernaux, J. (1966). In The Biology of Human Adaptability, p.9r. [P. T. Baker and J. S. Weiner, editors.] Oxford: Clarendon Press.

Macpherson, R. K. (1 966). In The Biology of Human Adaptability, p.43I. [P. 'T. Baker and J. S. Weiner, editors.] Oxford: Clarendon Press.

Tanner, J. M. (1966). In The Biology of Human Adaptability, p.45. [P. T. Baker and J. S. Weiner, editors.] Oxford: Clarendon Press.

Tobias, P. V. (1966). In The Biology of Human Adaptability, p.I I. [P. T. Baker and J. S. Weiner, editors.] Oxford: Clarendon Press.

Weiner, J. S. (1965). International Biological Programme : Guide to the Human Adaptability Proposals. IBP Handbook No. r. London: ICSU Special Committee for the International Biological Programme. 